\title{
A Study on the Individual Distance of a Small Robot Moving towards Adult Male and Female
}

\author{
Miyu Aoki and Akiko Watanabe \\ Department of Architecture, Tokyo Denki University, Tokyo 120-8551, Japan
}

\begin{abstract}
In Japan, robots are a regular feature of daily life and in rehabilitation support care and reporting on any emergencies involving the elderly. This study is on design guidelines for the living space with robots and can be applied to the architectural planning and focused on the basic environmental primary factor. The key terms were space, people-adult male and female, positions, and the robot-size, speed-settings and approaching angles. This research is the distances a small mobile robot moves to an adult male compared with that toward an adult female. The authors focus on a small mobile robot and identify the distances from which the robot can approach individuals, and also clarify how the distances to individuals change as the robot's speed and angle of approach varies. The study did this experiment to analyze 30 patterns per person and also when at an angle of the difference of male and female, two position standing/seated and three speed-setting- $0.08 \mathrm{~m} / \mathrm{sec}, 0.24 \mathrm{~m} / \mathrm{sec}$ and $0.48 \mathrm{~m} / \mathrm{sec}$ and five directions- $0^{\circ}, 45^{\circ}$, $90^{\circ}, 135^{\circ}$ and $180^{\circ}$.
\end{abstract}

Key words: Small mobile robot, individual distance, living space.

\section{Introduction}

Robots are a regular feature of daily life and in rehabilitation support care and reporting on any emergencies involving the elderly. The development of technology and information, and the aging of society in Japan is part of this greater presence. The authors' study is to provide guidelines that can be used by architects and those involved in designing living spaces that will include robots [1-3].

\section{Purpose}

The authors conducted basic research to fine design guidelines for those involved in architectural planning for living spaces with robots and focused on the basic environmental primary factor. The key terms were space, people-adult male and female, positions, and the robot-size, speed-settings and approaching angles.

The authors researched the distances a small mobile robot moves to an adult male compared with that toward an adult female [4]. A small mobile robot is

Corresponding author: Miyu Aoki, M.Arch., research student, research field: architecture planning. E-mail: 13ky006@ms.dendai.ac.jp. defined as the depth, width and height that each robot of $15 \mathrm{~cm}$ or less moves. The authors focus on a small mobile robot and identify distances at which the robot can approach individuals, and also clarify how the distances to individuals change as the robot's speed and angle of approach varies.

The sense of distance, including the personal space is a basic environmental primary factor in important architectural planning. To clarify the basic knowledge needed to plan living spaces, the authors need to first clarify the movement between people and robots as this is a symbiotic. And they focus on human artifact rather than the interpersonal versus human.

\section{Methods}

There were four experiments, an adult male and female in both standing and seated positions.

The experiment with adult males was done on July 21 and 26, people were selected for the trial with aged 18-24. The experiment with adult females was done on November 1 and 15 in 2010, and 28 people were selected for the trial with aged 19-21.

The distance was measured close to the small mobile 
robot as subjects gradually looked at the small mobile robot and indicated when they did not wish to be approached any further.

The authors did this experiment to analyze 30 patterns per person and also when at an angle of the difference of male and female, two position standing/seated and three speed-setting $-0.08 \mathrm{~m} / \mathrm{sec}$, $0.24 \mathrm{~m} / \mathrm{sec}, 0.48 \mathrm{~m} / \mathrm{sec}$ and five directions $-0^{\circ}, 45^{\circ}$, $90^{\circ}, 135^{\circ}, 180^{\circ}$. In addition, this experiment was set at a random pattern and got a wireless remote control to operate the subject which was tested in a way to stop the small mobile robot. In addition, those with trauma disorders were unable to walk or in this experiment (Tables 1 and 2 and Figs. 1 and 2).

\section{Result of Experimental 1}

\subsection{Impact Speed and Angle}

From data obtained from an experiment, the authors considered the distance between the adult male and the small mobile robot. In addition, the standard deviation was determined to be an indicator of the overall variability in the data because there was individual variation. The average value of the distance for each approach angle and speed of the subjects in standing and seated position is shown in Tables 3 and 4 and Figs. 3 and 4. As shown, the standing position to the rearward directions from the trend of upward-sloping, in the seated position is that where there is a long distance to the trend of falling forward from the upright position.

\subsection{Verification of Interaction of Angle and Speed}

As shown in Table 5 and Fig. 5, there is no special significance because there is not a valid probability, i.e., less than 0.05 , for small mobile robot approaching the adult male in either the standing and seated position. However, there is a difference of about ten times in the speed and angle, i.e., how the impact on speed is less than the impact angle. This considered, there is the angle than the speed in effect.
Table 1 Experimental settings.

\begin{tabular}{|c|c|c|c|c|}
\hline Speed & \multicolumn{4}{|c|}{ Approaching angle } \\
\hline $0.08 \mathrm{~m} / \mathrm{sec}$ & 0deg. & 45 deg. 90 deg. & $135 \mathrm{deg}$ & $180 \mathrm{deg}$. \\
\hline $0.24 \mathrm{~m} / \mathrm{sec}$ & 0 deg. & 45 deg. & 135 deg & 180 deg. \\
\hline $0.48 \mathrm{~m} / \mathrm{sec}$ & 0 deg. & 45 deg. & $135 \mathrm{deg}$ & $180 \mathrm{deg}$. \\
\hline
\end{tabular}

Table 2 Average data.

\begin{tabular}{lll}
\hline & Adult males & Adult females \\
\hline Average age & 21.7 & 21.4 \\
Average height & $172.1 \mathrm{~cm}$ & $158.3 \mathrm{~cm}$ \\
Average visual acuity & 0.9 both eyes & 1.0 both eyes \\
\hline & \multicolumn{2}{l}{ Measurement: } \\
\cline { 2 - 3 } & [width $\times$ depth $\times$ height] \\
$120 \mathrm{~mm} \times 130 \mathrm{~mm} \times 70 \mathrm{~mm}$ \\
Speed: \\
(1) $0.08 \mathrm{~m} / \mathrm{sec}$ \\
(2) $0.24 \mathrm{~m} / \mathrm{sec}$ \\
(3) $0.48 \mathrm{~m} / \mathrm{sec}$
\end{tabular}

Fig. 1 The robot conditions.

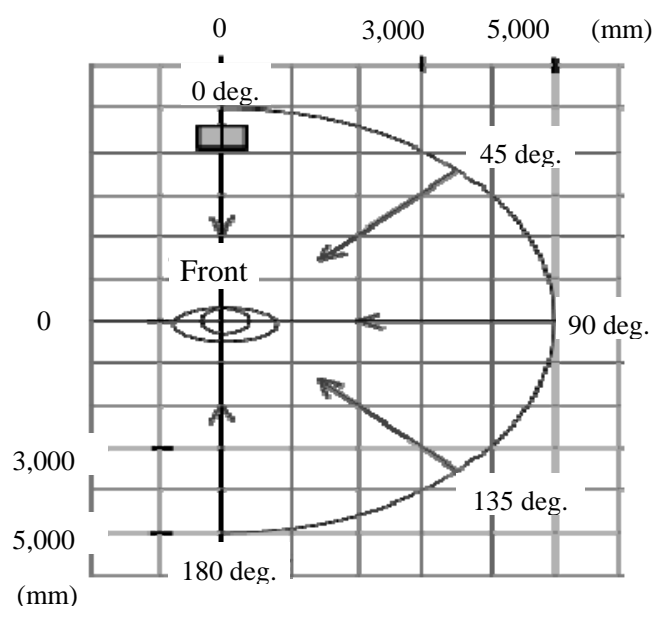

Fig. 2 Experimental venue.

Table 3 Individual distance of standing adult males.

\begin{tabular}{lrrrrr}
\hline \multirow{2}{*}{ Speed } & \multicolumn{5}{c}{ Approaching angle } \\
\cline { 2 - 6 } & 0 deg. & $45 \mathrm{deg}$. & $90 \mathrm{deg}$. & $135 \mathrm{deg}$. & $180 \mathrm{deg}$. \\
\hline $0.08 \mathrm{~m} / \mathrm{sec}(\mathrm{cm})$ & 122.4 & 145.7 & 142.6 & 153.7 & 157.0 \\
$0.24 \mathrm{~m} / \mathrm{sec}(\mathrm{cm})$ & 128.7 & 143.4 & 134.9 & 154.4 & 149.9 \\
$0.48 \mathrm{~m} / \mathrm{sec}(\mathrm{cm})$ & 142.9 & 147.2 & 141.8 & 158.0 & 154.0 \\
$\begin{array}{l}\text { Standard } \\
\text { deviation }\end{array}$ & 64.3 & 58.0 & 55.9 & 54.2 & 51.7 \\
\hline
\end{tabular}

4.3 Relationship of Individual Distance and the Posture

For the distance, with respect to the direction of $180^{\circ}$ which is from $0^{\circ}$ to $5^{\circ}$, is nearly $145 \mathrm{~cm}$ in the upright 
Table 4 Individual distance of seated adult males.

\begin{tabular}{lrrrrr}
\hline \multirow{2}{*}{ Speed } & \multicolumn{5}{c}{ Approaching angle } \\
\cline { 2 - 6 } & 0 deg. & 45 deg. & 90 deg. & 135 deg. & 180 deg. \\
\hline $0.08 \mathrm{~m} / \mathrm{sec}(\mathrm{cm})$ & 161.6 & 164.4 & 137.5 & 152.1 & 144.0 \\
$0.24 \mathrm{~m} / \mathrm{sec}(\mathrm{cm})$ & 157.9 & 157.1 & 138.3 & 145.9 & 145.9 \\
$0.48 \mathrm{~m} / \mathrm{sec}(\mathrm{cm})$ & 163.9 & 159.7 & 142.0 & 150.2 & 141.3 \\
$\begin{array}{l}\text { Standard } \\
\text { deviation }\end{array}$ & 58.5 & 58.7 & 56.2 & 58.6 & 58.3 \\
\hline
\end{tabular}

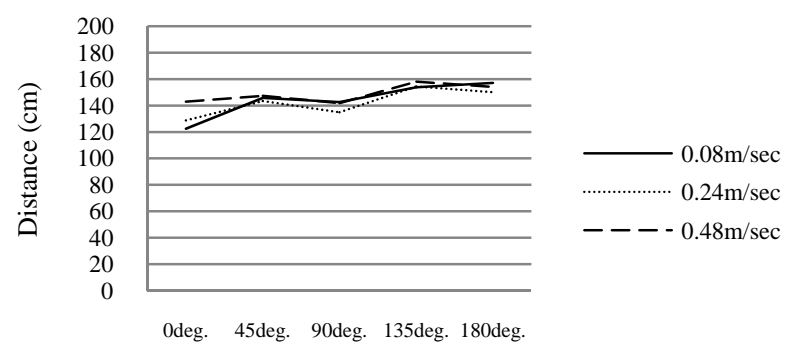

Fig. 3 Average graph of standing adult males.

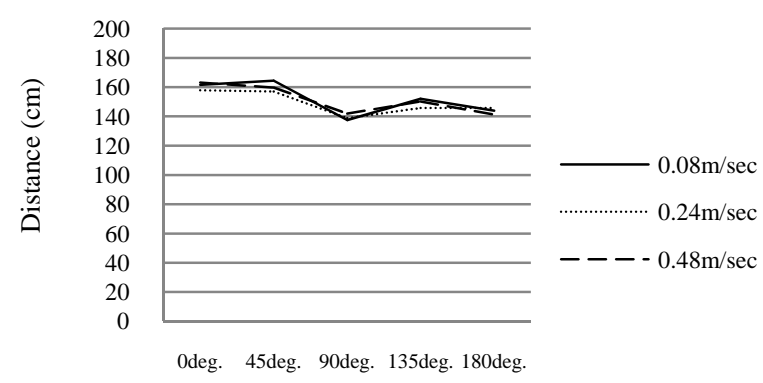

Fig. 4 Average graph of seated adult males. position. From each velocity minimum and maximum numbers of front and rear, which is $-12.5< \pm 0<23.1$. The distance is nearly $151 \mathrm{~cm}$ when seated from each velocity minimum and maximum numbers of the front and rear, which is $-13.6< \pm 0<13$.3.

\section{Result of Experimental 2}

\subsection{Impact Speed and Angle}

Similarly, representation of the average value of the distance for each approach angle and approach speed of the subjects in standing and seated position is shown in Tables 6 and 7 and Figs. 6 and 7. In the graph of the distance shows adult females it tends to differ by the speed of each individual as a whole. Thus, no major difference depending on the posture can be found.

\subsection{Verification of Interaction of Angle and Speed}

In Table 5, adult females are affected by the moving speed from the approach angle, the 5\% level of significance appears from the results of the test the main effect of speed was found. The approach from the study of multiple comparisons, in the standing position, in the case of $0.08 \mathrm{~m} / \mathrm{sec}$, and compared to $0.48 \mathrm{~m} / \mathrm{sec}$ speed found that slow speed could be closer to the experiments. The authors found that the seated position,
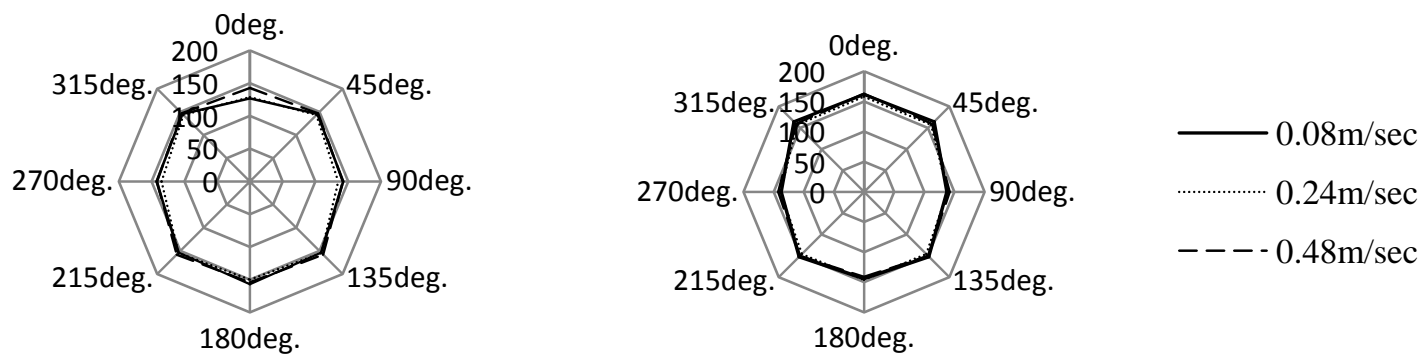

Fig. 5 Individual distance of adult males (cm).

Table 5 Verification of interaction of angle and speed in adult male.

\begin{tabular}{|c|c|c|c|c|c|c|c|}
\hline \multicolumn{4}{|c|}{ Upright } & \multicolumn{4}{|c|}{ Chair-sitting } \\
\hline & Speed & & Ingle & & Speed & & Angle \\
\hline $\begin{array}{l}\text { Main effect } \\
\text { test }\end{array}$ & $\begin{array}{l}\text { Significance } \\
\text { probability }\end{array}$ & $\begin{array}{l}\text { Main effect } \\
\text { test }\end{array}$ & $\begin{array}{l}\text { Significance } \\
\text { probability }\end{array}$ & $\begin{array}{l}\text { Main effect } \\
\text { test }\end{array}$ & $\begin{array}{l}\text { Significance } \\
\text { probability }\end{array}$ & $\begin{array}{l}\text { Main effect } \\
\text { test }\end{array}$ & $\begin{array}{l}\text { Significance } \\
\text { probability }\end{array}$ \\
\hline$F=0.422$ & 0.656 & $F=2.039$ & 0.088 & $F=0.082$ & 0.921 & $\mathrm{~F}=2.147$ & 0.074 \\
\hline
\end{tabular}


Table 6 Individual distance of standing adult females.

\begin{tabular}{lrrrrr}
\hline \multirow{2}{*}{ Speed } & \multicolumn{5}{c}{ Approaching angle } \\
\cline { 2 - 6 } & 0 deg. & 45 deg. 90 deg. & 135 deg. & 180 deg. \\
\hline $0.08 \mathrm{~m} / \mathrm{sec}(\mathrm{cm})$ & 115.4 & 126.2 & 128.0 & 130.4 & 138.8 \\
$0.24 \mathrm{~m} / \mathrm{sec}(\mathrm{cm})$ & 135.9 & 130.8 & 130.9 & 138.1 & 140.4 \\
$0.48 \mathrm{~m} / \mathrm{sec}(\mathrm{cm})$ & 140.6 & 143.8 & 142.6 & 138.1 & 142.1 \\
Standard & 52.3 & 45.3 & 44.9 & 43.7 & 56.9 \\
deviation & & & & & \\
\hline
\end{tabular}

Table 7 Individual distance of seated adult females.

\begin{tabular}{lrrrrr}
\hline \multirow{2}{*}{ Speed } & \multicolumn{5}{c}{ Approaching angle } \\
\cline { 2 - 6 } & 0 deg. & 45 deg. 90 deg. & 135 deg. & 180 deg. \\
\cline { 2 - 6 } $0.08 \mathrm{~m} / \mathrm{sec}(\mathrm{cm})$ & 120.5 & 120.8 & 119.3 & 130.3 & 131.7 \\
$0.24 \mathrm{~m} / \mathrm{sec}(\mathrm{cm})$ & 144.5 & 147.8 & 133.6 & 141.3 & 133.2 \\
$0.48 \mathrm{~m} / \mathrm{sec}(\mathrm{cm})$ & 151.2 & 149.2 & 147.2 & 148.3 & 138.0 \\
$\begin{array}{l}\text { Standard } \\
\text { deviation }\end{array}$ & 44.5 & 44.3 & 44.5 & 46.4 & 51.8 \\
\hline
\end{tabular}

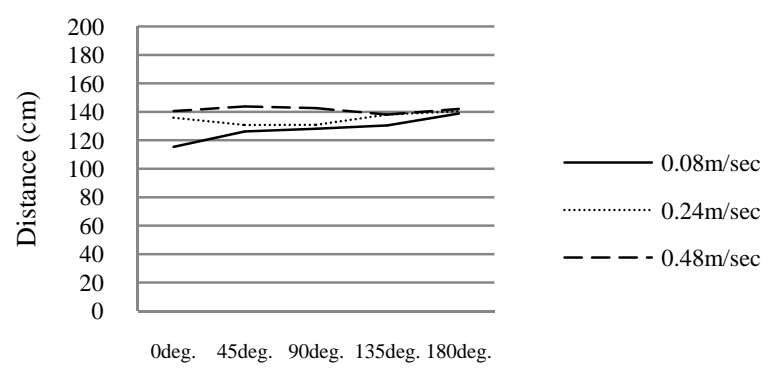

Fig. 6 Average graph of standing adult females.

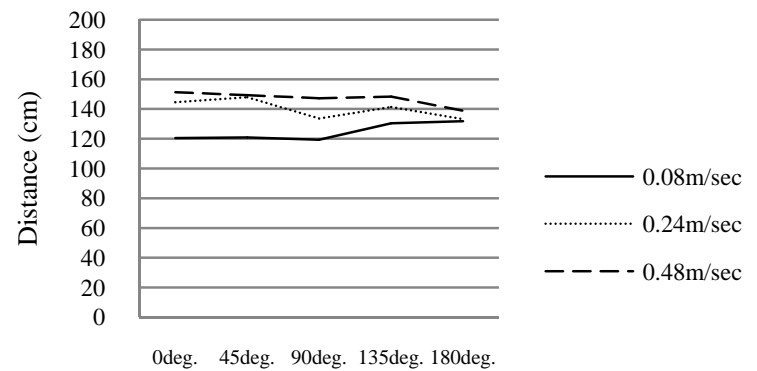

Fig. 7 Average graph of seated adult females.

and speed of $0.08 \mathrm{~m} / \mathrm{sec}$ is significant (Fig. 8 and Table 8).

\subsection{Relationship of Individual Distance and Posture}

Distance, with respect to the direction of $180^{\circ}$ from $0^{\circ}$ to $5^{\circ}$, is nearly $135 \mathrm{~cm}$ in the standing position. From each velocity minimum and maximum numbers of front and rear, which is $-19.6< \pm 0<11.4$. Furthermore, the distance is nearly $137 \mathrm{~cm}$ in the seated from each velocity minimum and maximum numbers of front and rear, which is $-17.8< \pm 0<14.2$.

\section{Consideration}

\subsection{Relationship of Angle and Speed for Small Mobile Robot}

As shown in the experiment, the adult male and adult female affected the approach angle and moving speed. The adult males affected by the approach angle slightly, and for the adult female there was an impact on the moving speed.

6.2 Difference by Positions between Adult Male and Female

A comparison of standing and seated positions, shows that the result indicated a different trend by adult male and female. Adult males have differences that depend on the positions, the direction in the standing position is before and in the direction in the seated position is from the back. However, for the adult female, there was no obvious change in the distance before and after depending on the position, but the effect on speed was remarkable. The effect of $0.08 \mathrm{~m} / \mathrm{s}$ was a large in seated position.

\subsection{Relationship of Individual Distance between Adult Male and Female}

A comparison of the individual distance in the positions, there is a difference of more than $10 \mathrm{~cm}$ is an upper limit of distance by gender, more adult female that a long distance for a small mobile robot (Fig. 9).

This is attributed to the small mobile robot such as the difference in the impression obtained from the questionnaire survey and the impact of height. In addition, compared to that revealed in the egg-shaped personal space of a conventional, near-circular shape is more positive than the sharp egg. In other words, the adult male and female should be a close distance, 

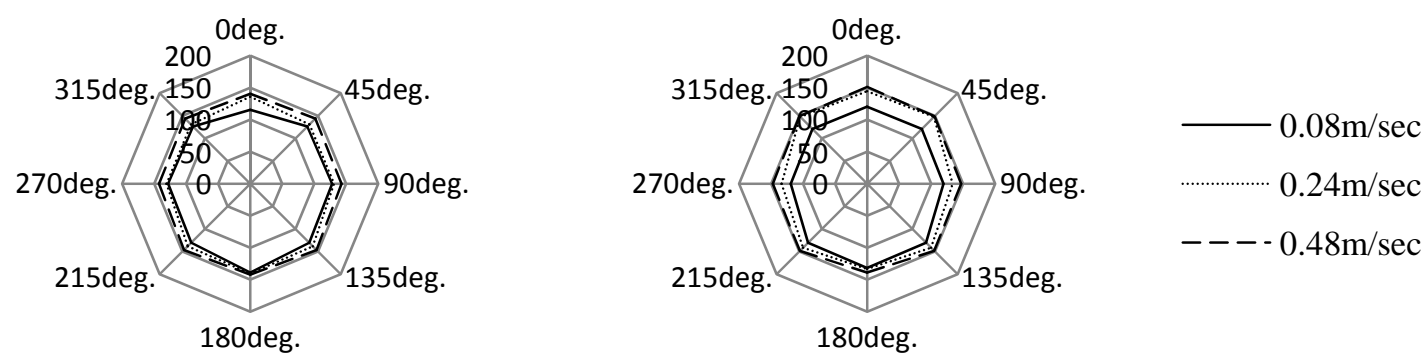

Fig. 8 Individual distance of adult females (cm).

Table 8 Verification of interaction of angle and speed in adult female.

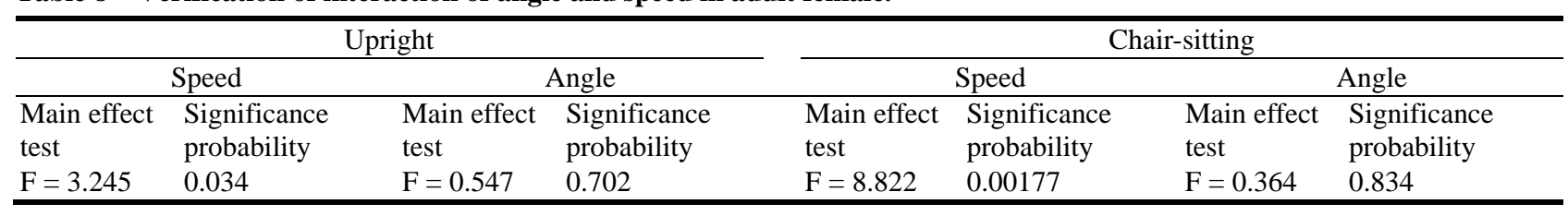
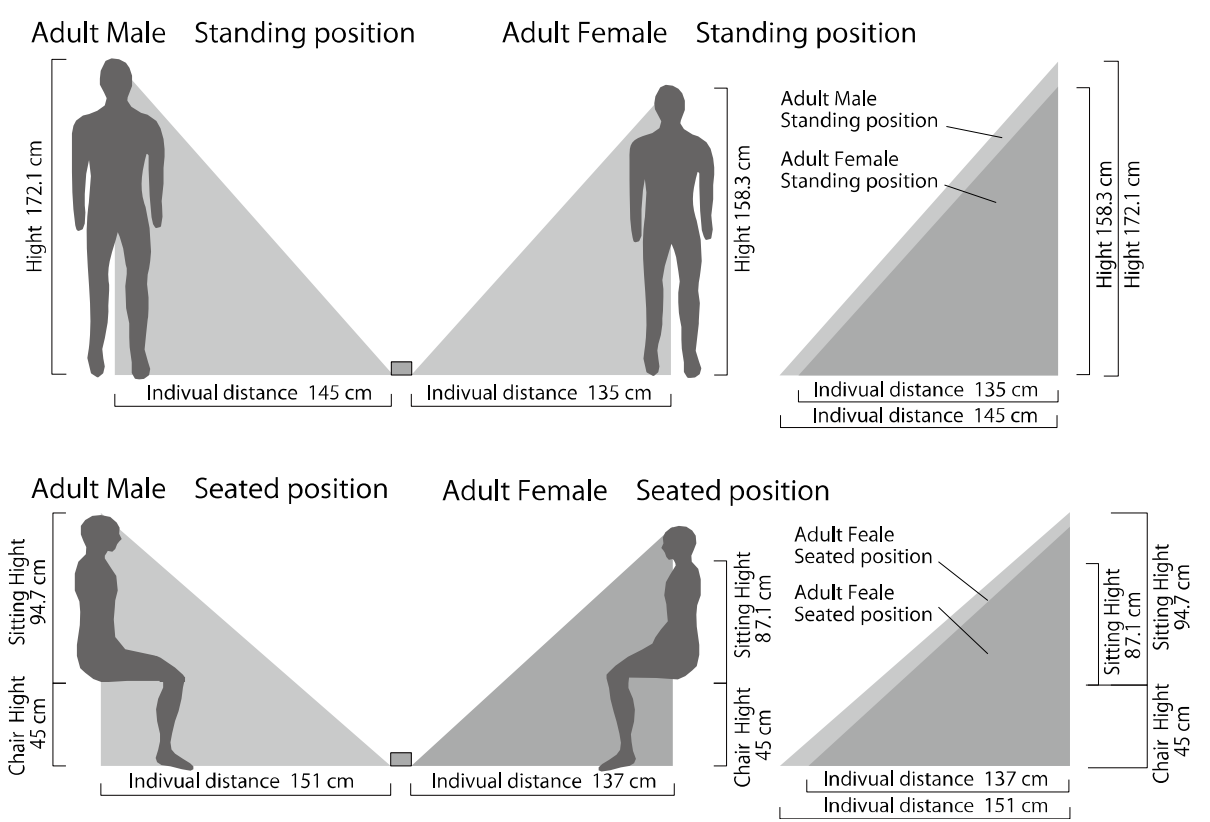

Fig. 9 Difference between approach adult male and females.

which should be roughly equal. The individual distance in this survey, to be in the range adjacent phase of social distance described by Edward Hall as the hidden dimension of 1.2-2.1 $\mathrm{m}$ [5].

\subsection{The Assignment for Architectural Planning}

When applied to housing space based on these things, the plan suggests that current layouts are too small. The architectural space requires enough space when it comes to coexistence with the robot.

\section{Conclusions and Future Prospects}

The following four results were obtained:

(1) The difference in adult male and adult female affected "approach angle" and "moving speed". The robot intentionality increased its speed when approaching the adult female;

(2) For the adult male, the obvious effect is not observed, but the impact on speed is less than the impact angle; 
(3) For the adult female, the robot tended to come closer to either individual when it was moving at 0.08 $\mathrm{m} / \mathrm{s}$ rather than at other speeds;

(4) Overall, the robot moved closer to people by tracing a semicircle with the person (male/female) at the center. It came to around $10 \mathrm{~cm}$ closer to the adult female than to the adult male.

The authors will continue research on design guidelines and architectural planning for living spaces, as well as conduct experiments on the basis of real public, and housing space. Further, the authors would like to experiment with robot that is customized to the needs of the user.

\section{References}

[1] A. Enta, H. Watanabe, T. Sano, K. Hayashida, A study of avoidable distance against robot, Journal of Architecture, Planning and Environmental Engineering 601 (2006) 81-85.

[2] K. Hayashida, A. Enta, Y. Yoshioka, M. Takahashi, Y. Sano, $\mathrm{H}$. Watanabe, Comfortable distance between the man and the autonomy robot, Journal of Architecture, Planning and Environmental Engineering 651 (2010) 1133-1140.

[3] Y. Yousuke, M. Thakahashi, H. Watanabe, A. Enta, Y. Sano, K. Hayashida, Characteristic behavior in follow-walking to leading robots, Journal of Architecture, Planning and Environmental Engineering 652 (2010) 1399-1406.

[4] M. Aoki, A. Watanabe, A study on the distances of an upright/chair-sitting small mobile robot to male adult individuals, Journal of Architecture, Planning and Environmental Engineering 664 (2011)1093-1100.

[5] E. Hall, The Hidden Dimension, Doubleday \& Company Inc., New York, 1966. 